1 Fundação Oswaldo Cruz (Fiocruz), Escola Nacional de Saúde Pública Sérgio Arouca (Ensp), Centro de Saúde Escola Germano

Sinval Faria - Rio de Janeiro (RJ), Brasil.

anafittipaldi@ensp.fiocruz.br

2 Universidade Federal do Rio de Janeiro (UFRJ), Departamento de Medicina de Família e Comunidade - Rio de Janeiro (RJ), Brasil. valromano@uol.com.br

${ }^{3}$ Fundação Oswaldo Cruz (Fiocruz), Escola Nacional de Saúde Pública Sérgio Arouca (Ensp), Centro de Saúde Escola Germano

Sinval Faria - Rio de Janeiro (RJ), Brasil.

barrosdc@ensp.fiocruz.br

\section{Nas entrelinhas do olhar: Apoio Matricial e os profissionais da Estratégia Saúde da Família}

\author{
Reading between the lines: Matrix Support and professionals of \\ Family Health Strategy
}

Ana Lúcia de Magalhães Fittipaldi1, Valéria Ferreira Romano ${ }^{2}$, Denise Cavalcante de Barros ${ }^{\mathbf{3}}$

RESUMO Trata-se de artigo fruto de pesquisa qualitativa cujo objetivo foi analisar os significados que os profissionais da Estratégia Saúde da Família atribuíam ao Apoio Matricial. Foram realizadas 18 entrevistas semiestruturadas e para interpretação dos resultados adotou-se a Análise de Conteúdo. Houve consenso sobre a importância do Apoio Matricial para a Estratégia Saúde da Família e que sua construção aconteceu mais no cotidiano e menos por uma questão normativa. Os profissionais identificaram ênfase no enfoque clínico e secundarização das ações de prevenção e coletivas, além de priorização dos núcleos de conhecimento, dificultando a interdisciplinaridade.

PALAVRAS-CHAVE Atenção Primária à Saúde; Estratégia Saúde da Família; Pesquisa qualitativa.

ABSTRACT This article is the result of a qualitative research that aimed to analyze the meanings assigned by the professionals of Family Health Strategy to Matrix Support. Eighteen semi-structured interviews were carried out and the results were interpreted through Content Analysis. There was consensus on the importance of Matrix Support for Family Health Strategy. It was also acknowledged that Matrix Support was more a result of an everyday practice and less due to a normative question. The professionals identified an emphasis on clinical aspects and a lesser focus on preventive and collective actions. They also pointed out a prevalence of knowledge nuclei, hindering interdisciplinarity.

KEYWORDS Primary Health Care; Family Health Strategy; Qualitative research. 


\section{Introdução}

O Ministério da Saúde criou, no ano de 2008, o Núcleo de Apoio à Saúde da Família (Nasf) com o objetivo de ampliar a abrangência e a resolutividade das ações das equipes da Estratégia Saúde da Família (ESF), bem como atuar no apoio especializado a elas (BRASIL, 2009).

As ações do Nasf são pautadas nas diretrizes da Atenção Básica (AB), quais sejam: ação interdisciplinar e intersetorial; educação permanente em saúde; educação popular; promoção da saúde; humanização; integralidade; participação social; e territorialização. Essas ações, por sua vez, incorporaram os conceitos de Apoio Matricial e de Equipe de Referência, que visam provocar mudanças nas relações de trabalho entre profissionais das equipes da ESF e profissionais especialistas (BRASIL, 2009).

A proposta de Apoio Matricial e Equipe de Referência foi desenhada com o objetivo de superar as limitações impostas pela organização tradicional dos serviços de saúde e ampliar as possibilidades de integração dialógica entre diversas especialidades (CUNHA; CAMPos, 2011). Sendo assim, o Apoio Matricial, desde sua concepção, atua para promover a retaguarda assistencial e o suporte técnico pedagógico de profissionais especialistas às Equipes de Referência, reforçando a vontade de mudanças nas relações de trabalho. A Equipe de Referência, composta por profissionais considerados essenciais para conduzir os problemas de saúde mais comuns da população, seria representada pela equipe da ESF, possibilitando um rearranjo organizacional de reforço ao trabalho em equipe multidisciplinar, deslocando, assim, o poder das profissões e corporações de especialistas (CUNHA; CAMPOS, 2011).

Para que o processo de Apoio Matricial possa ser de fato implementado, entretanto, há de se ressignificar e reestruturar algumas tecnologias de trabalho em saúde, a exemplo de práticas interdisciplinares, como é a interconsulta. Esta tem sido considerada como um dos principais instrumentos do Apoio Matricial, trazendo à tona seu profundo sentido de práticas interdisciplinares colaborativas, na direção de uma educação interprofissional (CHIAVERINI, 2013).

As experiências com Apoio Matricial encontradas na literatura nacional são recentes e relatam, via de regra, as dificuldades e potencialidades da inserção de profissionais especialistas na $A B$, através de equipes de Nasf, bem como a efetividade das ações do Apoio Matricial às equipes da ESF, ou mesmo sugerem propostas para melhor viabilizar a atuação do Nasf (BARBOSA, 2010; SANTOS, 2012; SILVA, 2012; OLIVEIRA 2012).

Esses mesmos estudos, semelhantes no que se refere ao objeto de pesquisa, apresentam temáticas recorrentes que têm sido relacionadas às dificuldades encontradas quanto à efetividade de ações interdisciplinares: a sobrecarga de trabalho, a alta rotatividade de profissionais, a formação profissional insatisfatória para as práticas em saúde coletiva, as barreiras de integração entre a equipe do Nasf e as equipes da ESF, o predomínio das ações clínicas individuais sobre as ações coletivas de prevenção e promoção da saúde e, por fim, a deficiente comunicação entre os níveis de atenção à saúde (BARBOSA, 2010; SANTOS, 2012; SILVA, 2012; OLIVEIRA, 2012).

Assim, o modo como o Apoio Matricial tem sido percebido por seus atores é uma questão que baliza nossas reflexões, seja por sua permeabilidade ou por certo ineditismo na produção da saúde do trabalho em equipe. Este artigo tem por objetivo apresentar a discussão que emergiu das reflexões sobre os significados que os profissionais da ESF e do Nasf atribuem ao Apoio Matricial, além da repercussão desses significados nas relações cotidianas de trabalho.

\section{Metodologia}

Apresentam-se aqui reflexões advindas de uma pesquisa qualitativa desenvolvida em 
duas unidades básicas de saúde de uma comunidade da zona norte do município do Rio de Janeiro.

Os participantes do estudo foram os profissionais das equipes da ESF, os gerentes das Clínicas da Família bem como os profissionais do Nasf. Os critérios para seleção foram baseados na representatividade que os conhecimentos, experiências e atitudes dos profissionais exercem sobre a questão motivadora da pesquisa. Assim, foi fundamental que todas as equipes da ESF fossem representadas por, pelo menos, um profissional.

Outros critérios de inclusão foram: o tempo de atuação na $\mathrm{AB}$ e/ou na ESF, uma vez que vivenciar a transição entre modelos distintos influencia a maneira de lidar com as novas propostas de trabalho; as diferentes formações técnicas dos profissionais, acreditando-se que as concepções específicas de cada núcleo profissional influenciam o trabalho em equipe e a maneira de entender a atuação do apoio especializado; e, por último, a disponibilidade dos profissionais em contribuir com a pesquisa.

A inclusão dos profissionais do Nasf teve por objetivo identificar a interação destes com a ESF, dentro da concepção do Apoio Matricial. Além disso, a inserção dos gerentes das Clínicas da Família foi estratégica, entendendo que a gerência, na perspectiva da ESF, é um elemento inserido no movimento de transformação do modelo assistencial.

Optou-se por utilizar a entrevista semiestruturada como técnica de coleta de dados para melhor preservar a liberdade de expressão dos entrevistados. Essa técnica adota um roteiro como referência que possibilita flexibilização dos questionamentos, abrindo espaço para diversos e divergentes sentidos sobre o tema de entrevista proposto (FLICK, 2009; MINAYO, 2010). Sendo assim, nosso roteiro de entrevistas pretendeu nortear alguns questionamentos, a saber: como é o entendimento dos profissionais da ESF, do Nasf e dos gerentes das Clínicas da Família sobre Apoio Matricial; quais as dificuldades e potencialidades encontradas no cotidiano das unidades de saúde/equipes; se esse método de trabalho atende às demandas das equipes e da população.

O método selecionado para tratamento dos dados, análise e interpretação dos resultados foi uma adaptação da Análise de Conteúdo, na sua vertente temática, que infere um tema como conceito central e o desmembra em subtemas, considerando o que as entrevistas revelaram (BARDIN, 2011; MINAYO, 2012).

A Análise de Conteúdo temática foi realizada em três etapas: pré-análise, exploração do material e interpretação dos resultados (BARDIN, 2011). Durante a pré-análise foi realizada uma leitura exaustiva do material com o objetivo de obter uma visão de conjunto inicial e identificar as categorias para classificação das falas. Em seguida, durante a exploração do material, foi feita a análise em si, classificando as falas ou fragmentos selecionados de falas entre as categorias de análise. Dando continuidade, foram identificados núcleos de sentido em cada categoria empírica que, juntamente com os pressupostos teóricos iniciais, apontaram os temas em torno dos quais foi realizada a análise interpretativa dos depoimentos.

A pesquisa foi aprovada pelo Comitê de Ética em Pesquisa (CEP) da Ensp/Fiocruz, sob Parecer $n^{0}$. 178.224 em 19 de dezembro de 2012 e cumpre as disposições da Resolução $n^{\circ}$. 196/96, referente a pesquisas envolvendo seres humanos (BRASIL, 1996).

\section{Resultados e discussão}

A pesquisa de campo envolveu 18 entrevistas realizadas com um representante de cada equipe da ESF, dois profissionais do Nasf e com os dois gerentes das unidades de saúde, com as seguintes formações acadêmicas: nove enfermeiros, oito médicos e um profissional de outra categoria. 
Os resultados são apresentados e discutidos a seguir, dispostos em categorias de análise e seus respectivos temas que emergiram das entrevistas a partir da interpretação das autoras. Algumas falas dos entrevistados foram aqui reproduzidas, na intenção de melhor descrever e implicar o leitor com o assunto, sendo identificadas por letras, conforme inserção profissional, e numeradas aleatoriamente: (E): profissionais das equipes da ESF; (N): profissionais do Nasf e (G): gerentes das Clínicas da Família.

As categorias de análise identificadas foram: concepção e prática do Apoio Matricial e processo de trabalho do Nasf.

\section{Concepção e prática do Apoio Matricial}

A partir dessa categoria de análise, procurou-se compreender o entendimento que os profissionais atribuíram ao Apoio Matricial e como este foi construído no cotidiano das equipes.

Identificaram-se três temas nessa categoria empírica, a saber: princípios e diretrizes do Nasf (educação permanente, resolutividade, corresponsabilização, integralidade e interdisciplinaridade); construção do trabalho do Apoio Matricial na prática do cotidiano e predomínio do modelo biomédico influenciando a prática do Apoio Matricial. A seguir, apresentam-se as reflexões que surgiram a partir desses temas.

Alguns princípios e diretrizes que compõem o Nasf foram destacados pelos entrevistados na sua concepção sobre Apoio Matricial. Dentre eles, a educação permanente foi pontuada como relevante, considerando seu potencial de qualificação das práticas em saúde e de reorganização do processo de trabalho, conforme demonstra o seguinte depoimento:

Nas equipes em que eu tô há mais tempo, [...] essas pessoas não precisam me chamar porque elas mesmas já sabem o que fazer. Porque uma das coisas do matriciamento é tipo um treinamento em serviço. Você conseguir ajudar aquela pessoa que está ali, porque eu não estou todos os dias. Pra que, quando eu não esteja e ela pegue um caso semelhante, já possa nortear ela. (N1).

De acordo com o 'Cadernos de Atenção Básica - Diretrizes do Nasf', o Apoio Matricial apresenta duas dimensões: uma assistencial, que irá produzir ação direta sobre as necessidades dos usuários, e outra técnico-pedagógica, com responsabilidade de produzir apoio educativo para as equipes da ESF, compartilhando seu conhecimento específico com toda a equipe. Dessa forma, a educação permanente entra como uma importante dimensão do apoio, sem a qual a troca de saberes entre os profissionais ficaria descontextualizada da prática dos serviços (BRASIL, 2009).

Nas falas dos profissionais entrevistados, observou-se que o Apoio Matricial é compreendido como um potencializador das ações da ESF, aumentando a resolutividade da AB. Destacam, ainda, a corresponsabilização pelo cuidado prestado à população como essencial na concepção de apoio. "Pra mim a história de apoiar é fundamental. Acho que tem a ver com se responsabilizar junto. Corresponsabilizar. Não entendo o apoio do Nasf como um apoio parecerista" (E10).

Apoio Matricial é um apoio à equipe na tentativa de aumentar a capacidade da equipe de resolutividade e também dividir o problema, compartilhar as responsabilidades, dividir angústias, pensar conjuntamente o caso. (E3).

Para atingir o objetivo previsto com a criação do Nasf, além do compartilhamento dos saberes e trocas entre especialistas e Equipe de Referência, está prevista a construção compartilhada de diagnósticos e medidas terapêuticas, ou seja, a gestão compartilhada do cuidado (BRASIL, 2009). A responsabilidade sobre os casos não deve ser diluída nem transferida por 
meio de encaminhamentos, mas, ao contrário, também compartilhada, mantendo o vínculo do usuário com a Equipe de Referência, que poderá, assim, ofertar um cuidado longitudinal (OLIVEIRA, 2012). Dessa maneira, se o compartilhamento da gestão tende a desenvolver a corresponsabilização entre profissionais e usuários, infere-se que os entrevistados valorizam esse tema como fundamental, indo a favor do preconizado pelo Ministério da Saúde. Em relação à integralidade do cuidado, os profissionais demonstraram que a entendem e a valorizam enquanto uma diretriz a ser seguida não só pelas equipes da ESF, mas também pelo Nasf, conforme menciona um entrevistado:

É uma maneira que eu tenho de ver o paciente como um todo. A saúde da família, ela não enxerga só a doença, né? Você tentar fazer ação de prevenção também. Então, assim, o Apoio Matricial, você tem vários profissionais, cada um com especialidades, podendo fazer ação, discutir o paciente. Então é como se fosse uma parceria. Pra poder fazer a prevenção das doenças, ou quando já tem a doença, fazer o acompanhamento. (E5).

Durante as entrevistas, a interdisciplinaridade não foi destacada como um dos princípios do processo de trabalho do Nasf, apesar de ter sido valorizada a sua função de apoio nas questões do cotidiano, quando as equipes encontravam dificuldades no seu processo de trabalho. No entanto, uma das raras falas sobre interdisciplinaridade, citada abaixo, sinaliza que algum entendimento latente sobre ela estava presente:

[...] então quando juntam os dois conhecimentos distintos, né? Porque a enfermagem tem uma formação bem diferente do médico. Então, quando você consegue juntar os dois, unir e daí sair um produto final, acho bem bacana. $E$ a gente consegue isso. A discussão do caso clínico é bem legal. E com a percepção de cada formação. Eu acho bem interessante. Só tem a acrescentar. (E7).
O trabalho entre as Equipes de Referência e a equipe de matriciadores, dentro das diretrizes do Apoio Matricial, prevê um constante diálogo que irá propiciar um novo construto, a partir da incorporação do conjunto de saberes, habilidades e atitudes de cada profissional. Assim, entende-se que a interdisciplinaridade deveria estar presente no discurso e na prática como forma de interação dinâmica entre saberes, contribuindo para a redução da fragmentação do cuidado (DIAS, 2012).

Com relação ao tema sobre a construção do trabalho do Apoio Matricial na prática do cotidiano, as entrevistas revelaram que alguns profissionais não tinham clareza sobre suas atribuições dentro do Apoio Matricial. Os apoiadores e os profissionais das Equipes de Referência foram experimentando e aprendendo suas funções na prática profissional, através de uma construção coletiva, como revela a seguinte fala:

[...] na verdade saiu uma Portaria, baixou, tinha que ser cumprida e ninguém sabia como ia ser feito. Ninguém sabia o que tinha que ser feito. Acho que a gente foi buscando isso na prática. Uma construção. (N1).

Sendo ainda um processo em construção, em algumas situações, principalmente durante as consultas conjuntas, ficou evidenciado que alguns profissionais não entendiam como compartilhar saberes e sair da posição de espectadores passivos, participando ativamente com seus próprios conhecimentos e habilidades nas consultas.

Cabe aqui esclarecer que os entrevistados transpareceram certa desvalorização ou pouco entendimento sobre o atendimento conjunto. Este momento tem sido considerado um espaço fundamental para a educação permanente e o compartilhamento da clínica no Apoio Matricial, possibilitando uma rica troca de saberes e de práticas em ato, propiciando um ganho de experiências para todos os profissionais envolvidos (SARAIVA, 2012). O discurso a seguir reflete que ainda é incipiente o 
aproveitamento da consulta conjunta como facilitadora do processo de trabalho das equipes:

[...] mas já chegou pra mim em alguns momentos pessoas relatando que não viam sentido em ter interconsulta com a nutrição, porque, como o caso do cardiologista, é muito específico, então ficavam bastante como observador. Então, alguns profissionais relataram que preferiam como era antes, né? 'Por que não faz como era antes? Porque $a$ gente não tem grande participação. A gente fica ouvindo a consulta, as orientações e às vezes até atrapalha, perde tempo, enrola, você fica ali tendo que atender um monte de gente e tem que ficar sentado ali com o nutricionista, e não precisava estar ali, porque ela tá fazendo a parte dela e eu podia estar fazendo outras coisas'. (G1).

Quanto ao tema que trata do predomínio do modelo biomédico influenciando a prática do Apoio Matricial, os entrevistados relataram que ele parece estar fortemente presente no processo de trabalho das equipes. Certamente, como reflexo de uma formação em saúde ainda focada mais no aspecto biológico e menos no campo ampliado de saúde. Segundo os entrevistados, a prática do Apoio Matricial teve maior enfoque nas consultas conjuntas, dentro da unidade de saúde, que, apesar de serem feitas através de um atendimento compartilhado, reforçam o olhar sobre a doença, e não sobre o sujeito (CAMPOS, 2007), como demonstra o seguinte relato:

\section{[...] acaba sendo um atendimento mais específi- co, mais clínico, mais clínico, muito mais clínico. Porque não deixa de centralizar na doença, num primeiro momento. Porque a gente do Nasf, as pessoas vão acionar, na visão de quem aciona, num primeiro momento pra resolver um pro- blema de doença. Depois a gente entra naquele olhar ampliado, né? (N1).}

Infere-se que, além das consultas conjuntas, as demais ações do processo de trabalho do Apoio Matricial parecem ser pouco utilizadas pelas equipes, ou pouco compreendidas em seu potencial e metodologia, como visto a seguir: "Grupos eu nunca utilizei. Eles disponibilizam, mas eu nunca utilizei. A visita domiciliar em alguns casos que a gente precise a gente pode solicitar. Mas difícil porque eles têm várias equipes pra dar conta" (E14).

A atividade educativa no momento, a nossa equipe está se programando pra tornar isso mais eficiente, porque a gente já fez alguns grupos. Não tivemos muita adesão dos nossos usuários. Eu diria até que por uma falta de costume deles, de não ter tido isso há mais tempo. (E8).

O processo de trabalho do Apoio Matricial pode ser organizado, em conjunto com a Equipe de Referência, através de várias ações além das consultas conjuntas, como ações no território que envolvam trabalhos educativos, Projeto de Saúde no Território, Projeto Terapêutico Singular, ações junto aos equipamentos públicos como escolas, creches, igrejas, entre outros (BRASIL, 2009).

Os resultados encontrados por meio desses depoimentos são corroborados por outros estudos semelhantes, que evidenciam que os atendimentos clínicos são predominantes sobre outras ferramentas de matriciamento, como atendimento domiciliar, discussão e elaboração de planos terapêutiCOS (OLIVEIRA, 2012; IILVA, 2012), o que certamente limita o trabalho com a comunidade.

\section{Processo de trabalho do Nasf}

A partir dessa categoria de análise, pretendeu-se compreender como o Apoio Matricial efetivamente vinha sendo realizado pelas equipes, identificando as potencialidades, dificuldades e expectativas dos profissionais.

Os temas empíricos identificados foram: a abordagem do Nasf; a ESF como modelo de reorganização da $\mathrm{AB}$, gerando excesso de atribuições aos profissionais; a formação de recursos humanos em saúde; e as diferenças 
percebidas no processo de trabalho entre as duas unidades de saúde pesquisadas.

Com relação ao tema sobre a abordagem do Nasf, os profissionais entrevistados assumiram que o foco deveria ser o compartilhamento das ações, entendendo que, dessa forma, haveria uma maior efetividade do cuidado prestado ao usuário. No entanto, questionaram a qualidade da consulta conjunta em função do tempo que é disponibilizado para a sua realização, fazendo supor ser este um limitador do trabalho, como revelam as falas: "Eu preferia que sempre tivesse em conjunto, né? A gente acaba ficando muito responsável pelos pacientes mesmo, né? Então no vínculo que a gente faz eu quero saber o que o outro vai falar lá" (E10).

Eu acho que no caso da nutrição, esse tempo da consulta influencia. Eu não sei se dá pra fazer uma consulta boa de nutrição em 20 minutos. Então eu acho complicado, eu acho impossível, não sei. Eu penso como eu vou fazer uma interconsulta de 20 minutos com a psicologia? (E10).

Segundo a Portaria que criou o Nasf (BRASIL, 2009), a responsabilização pela comunidade deve ser compartilhada entre as equipes da ESF e a equipe do Nasf. Ela prevê, ainda, a revisão da prática do encaminhamento com base nos processos de referência e contrarreferência, não substituindo, mas ampliando-a para um processo de acompanhamento longitudinal das famílias. Dessa forma, o Apoio Matricial pressupõe a integração e o trabalho colaborativo entre os profissionais e a democratização das relações de trabalho (SARAIVA, 2010).

As intervenções individuais foram citadas como necessárias em alguns casos que ultrapassam a capacidade das equipes de resolução, porém mais para algumas especialidades do que para outras, determinadas pelas características do próprio núcleo de conhecimento, conforme mencionam os profissionais:

Eu acredito que o Nasf dá o apoio que pode, compartilha o que pode ser compartilhado, mas eu acho também que tem outras necessidades. Eu acho que precisa de um olhar individual. Por mais que você fale parece que você esgota o que você tem a falar. Uma outra visão. (E1).

Acho que só algumas. Eu acho que a cardiologia [...] com a interconsulta tá funcionando perfeitamente. A psicologia, ela tem momento individual, faz só o primeiro atendimento com a gente depois ele vai dando seguimento individual, e achamos que tá dando certo também. [...] mas algumas especialidades como a psiquiatria, que é difícil... Acho que poucos profissionais da Saúde da Família vão conseguir lidar com doentes que têm esses problemas. (E9).

Segundo a legislação específica sobre o assunto, as intervenções diretas e individualizadas dos profissionais do Nasf frente aos usuários deverão ocorrer somente em situações extremamente necessárias, sempre sob encaminhamento e acompanhamento das Equipes de Referência (BRASIL, 2009).

No entanto, a decisão sobre o grau de abordagem dos apoiadores, seja através do matriciamento às Equipes de Referência ou por meio de atendimentos individuais, deverá ser pactuada entre os profissionais envolvidos, garantindo que este profissional seja o responsável por ambas as abordagens (SARAIVA, 2010).

Quanto ao tema referente à ESF como modelo de reorganização da $\mathrm{AB}$ gerando excesso de atribuições aos profissionais, os entrevistados relataram excesso de atribuições, dificultando uma ampliação do olhar para a produção da integralidade do cuidado. Reiteradamente, as ações preventivas e de promoção da saúde parecem ser relegadas a um segundo plano em relação às ações curativas, colocando em dúvida a resolutividade do trabalho, como as falas seguintes revelam:

[...] agenda hiperlotada, cobrança das metas, indicador. Tem que dar conta daquilo ali, sobra muito pouco, a gente é engolido por essas coisas, 
consulta individual, doença e pouco é feito em relação. A gente tenta, se esforça até faz a prevenção. O que seria o nosso foco acaba desvirtuando. Tem que dar conta disso também, faz parte da nossa atribuição também. Eu costumo dizer que 40h é pouco. (E4).

[...] A gente tem essa tendência de fazer um planejamento sem ouvir, já chega com tudo pronto. O que seria legal para eles em relação à alimentação, né? O mundo ideal seria isso, a gente conseguir fazer uma agenda de trabalho não só com a nutrição, mas com a equipe, com a comunidade, com a educação, pensar nisso, numa coisa de rede mesmo, interligado, de vários setores... (G1).

Uma carteira de serviços, que eu acho que extrapolou a atenção básica. Eu acho que tem coisa além do que a gente realmente precisa fazer. Eu acho que se a gente ficasse mais na $A B$ mesmo a gente poderia produzir numa maneira mais eficiente, eu não digo tanto em número, mas em qualidade, né? Todo mundo quer qualidade, né? Números é produção. (E9).

Outro ponto relatado pelos entrevistados foi que o excesso de atribuições limitaria a interação entre apoiadores e equipes, justificando menor demanda dos apoiadores no cotidiano do trabalho. "Uma crítica que eu faço é que o Nasf tem que ter um papel mais proativo, e não tão passivo. Porque com o problema de tempo que a gente tem, se o Nasf não tiver um papel mais proativo, de estar lá do lado da equipe...”(E3).

Eu aciono menos do que eu gostaria. Porque eu tenho uma correria no dia-a-dia, a correria atrapalha muito. Muitas vezes eu quero fazer uma interconsulta, mas o tempo que a interconsulta vai me demandar inviabiliza a continuidade do atendimento de manhã. (E3).

Segundo a Política Nacional de Atenção Básica (PNAB) (BRASIL, 2012), a ESF deve ser a porta de entrada preferencial para o sistema de saúde, tendo a função de ordenadora da
Rede de Atenção à Saúde (RAS) e coordenadora do cuidado. Assim, existe uma grande expectativa em torno do papel da ESF para a reestruturação do sistema de saúde no Brasil.

Além disso, existe o processo de apropriação das equipes do conceito de Clínica Ampliada na prática profissional cotidiana que, somados a uma demanda reprimida da população por cuidados clínicos, acabam por gerar uma sobrecarga de trabalho e de responsabilidades para as equipes que nela atuam. Pode-se acrescentar ainda que a maioria dos contratos de gestão enfatiza a dimensão quantitativa do trabalho em saúde, representada pelo número de consultas e procedimentos clínicos realizados por turnos de trabalho (CUNHA; CAMPOS, 2011).

Com relação ao tema sobre a formação de recursos humanos para o Sistema Único de Saúde (SUS), cabe registrar que o Apoio Matricial, por meio de sua diretriz técnico-pedagógica, tem uma importante função, e alguns profissionais entrevistados reconheceram esse lugar como relevante:

Eu nunca trabalhei sem o Apoio Matricial. O grupo
foi muito importante pra minha formação... quando
chegava alguém o Apoio Matricial ficava mais pró-
ximo daquele profissional. [...] eu fui formado como
médico de família pelo Apoio Matricial. (E3).

O Nasf é considerado um potencial espaço de ensino, o que vai ao encontro das Diretrizes Nacionais Curriculares que preconizam que a formação profissional em saúde seja pautada nas necessidades e princípios do SUS, formando profissionais aptos a atuar nos sistemas de saúde (BRASIL, 2001).

Apesar disso, a formação profissional é ainda uma das dificuldades identificadas no processo de trabalho do Nasf, uma vez que não está voltada para as necessidades do SUS, em particular para a realidade da $\mathrm{AB}$ (NASCIMENTO, 2010). A proposta da Residência Médica e Multiprofissional em Saúde da Família tem sido considerada uma estratégia para reverter essa dificuldade, formando profissionais 
inseridos no contexto das práticas do trabalho das equipes da ESF e do Nasf.

$\mathrm{O}$ último tema refere-se às diferenças percebidas no processo de trabalho entre as duas unidades de saúde pesquisadas. Os entrevistados destacaram as características do seu corpo profissional bem como a organização do seu processo de trabalho como sendo significativas, repercutindo no cotidiano de trabalho das equipes e influenciando a prática do Apoio Matricial:

[...] trabalhar com saúde da família, mas numa unidade mista que você tem a todo o momento uma dicotomia, isso é muito complicado. Tem gente que fala: 'não, poxa, uma unidade mista é difícil'. É, mas tem suas compensações. Você consegue coisas que você não conseguiria numa unidade que tenha só saúde da família. Porque quando você precisa você tem o parceiro aqui do lado. Isso é bom. (E1).

[...] faz uma diferença você estar numa clínica que é só uma Clínica da Família. É diferente. Você tem outras possibilidades aqui [Centro de Saúde]. Aqui os médicos da família, eles podem literalmente acionar outras especialidades, outros conhecimentos, porque está próximo daqui [...]. Lá [Clínica da Família] não se consegue tão fácil assim. Os pacientes de lá tem dificuldade. Quem traz eles pra cá somos nós do Nasf. Por exemplo, eu trago, eu atendo aqui. (N2).

As unidades de saúde contempladas nesse estudo possuíam características bem distintas uma da outra. Ambas são Clínicas da Família, tendo uma delas particularidades por estar alocada no espaço físico de um centro de saúde nos moldes tradicionais.

As facilidades relatadas pelos profissionais que atuam no centro de saúde parecem dificultar a mudança da lógica do encaminhamento para o compartilhamento das ações, principalmente através das consultas conjuntas, uma vez que os profissionais já estão habituados a encaminhar os usuários para o agendamento individual.
Assim, conforme ressaltam em seu estudo Ballarin, Blanes e Ferigato (2012), a prática do Apoio Matricial demonstra estar sustentada não apenas por sua concepção teórica, mas principalmente pela construção coletiva entre os profissionais envolvidos e marcada pelas singularidades de cada unidade de saúde (BALLARIN; BLANES; FERIGATO, 2012).

\section{Considerações finais}

Este estudo revelou um aspecto da compreensão dos profissionais que atuam na ESF de uma comunidade do Rio de Janeiro sobre o Apoio Matricial e a sua inserção no cotidiano do trabalho das equipes. Tornar público o que pensam ratifica para todos que o sucesso de uma política pública só se faz, em ato, se os profissionais envolvidos na sua execução puderem opinar e serem ouvidos. Fazê-los pensar e falar sobre o cotidiano de seu trabalho com o Nasf e com o Apoio Matricial, seus nós críticos e suas potencialidades, parece ter sido uma importante estratégia, pois possibilitou certa desconstrução e ressignificação sobre o tema.

A pesquisa revelou que os profissionais entrevistados, apesar de possuírem diferentes sentidos sobre o conceito de Apoio Matricial, mantiveram reconhecimento, em consenso, a respeito da sua importância para as ações da ESF, confirmando ser esta uma abordagem acertada, quando se valoriza o processo de trabalho com foco no cuidado.

A resolutividade, a integralidade, a corresponsabilização, a interdisciplinaridade e a educação permanente foram identificadas como princípios e diretrizes que deveriam ser potencialmente seguidos por todos os envolvidos na ESF, tanto para a equipe do Nasf quanto para as Equipes de Referência. Assim, apontaram um elo que justifica o trabalho desenvolvido com objetivos em comum e em consonância com a PNAB.

Destaca-se que a interdisciplinaridade é um conceito ainda distante da prática nos 
serviços de saúde, refletindo as dificuldades dos profissionais do Nasf e das Equipes de Saúde da Família de saírem do seu núcleo de conhecimento ampliando o olhar para o campo de atuação. Da mesma forma, ficou explícito que os profissionais da ESF acionam o Apoio Matricial para atender uma demanda específica que aquele núcleo de saber, supostamente, será capaz de suprir.

Compartilhar saberes implica na articulação de núcleos disciplinares bastante distintos entre si e em lidar com a tendência de encerramento em si mesmo dos conhecimentos, desafios postos para a formação dos futuros profissionais de saúde.

Apesar da prática do matriciamento ter sido identificada por alguns atores como já sendo exercida antes de se tornar oficial no cenário da pesquisa, alguns conflitos criados poderiam ser compreendidos na medida em que se identifica que o Apoio Matricial, enquanto política pública, foi inserido no processo de trabalho da ESF pesquisada sem que os profissionais estivessem qualificados para compreender suas atribuições nessa nova metodologia de trabalho.

A clareza sobre o papel que cada um desempenha, como cada profissional se relaciona com o outro e com o próprio processo de trabalho nos parece ser central para a agenda cotidiana de trabalho e para a formação profissional das equipes. Esse parece ser um caminho que poderia contribuir para que a prática do Apoio Matricial fosse fortalecida e construída na direção do compartilhamento, afastando-se, assim, de certa informalidade que produz pedidos de ajuda entre profissionais sob a dependência de afinidades e bons relacionamentos interpessoais, o que certamente minimiza conflitos, mas não cria profissionalismo.

Nota-se que o discurso voltado para o modelo biomédico, centrado na doença, ainda é predominante nas práticas em saúde, o que fragiliza a concepção de Clínica Ampliada e os preceitos de promoção da saúde, distanciando o cuidado integral como foco do trabalho.
O excesso de atribuições e, consequentemente, uma menor disponibilidade de tempo, evidenciando frustrações dos profissionais que esperavam poder aplicar uma visão ampliada do processo saúde-doença-cuidado no seu cotidiano, aparecem como um alerta. Precisa-se fazer escolhas ou, pelo menos, melhor compreender as relações que se estabelecem entre qualidade e quantidade de atendimentos na ESF.

A partir de trocas na formação profissional em saúde, práticas compartilhadas e reflexões que envolvam uma produção da saúde interprofissional, incluindo gestores, trabalhadores e usuários, pode-se enfrentar as limitações ainda hoje encontradas para o desenvolvimento do Apoio Matricial. Nesse sentido, encontra-se implícito nas falas dos entrevistados um pedido de ajuda aos profissionais do Nasf, para que sejam proativos e se aproximem mais das equipes, participem e auxiliem a ESF na efetividade de uma abordagem ampliada do cuidado em saúde.

As opiniões sobre como deve ser a abordagem do Nasf junto às equipes não expressaram consensos, remetendo a uma discussão sobre os limites entre quais atribuições e competências são exclusivas de cada núcleo de saber e aquelas que podem e devem ser compartilhadas entre todos os profissionais das equipes. Para alguns, o compartilhamento das ações foi considerado a melhor maneira do Nasf organizar sua abordagem, enquanto apoio. Para outros, entretanto, as ações individualizadas, diretamente entre usuário e apoiador, sem necessariamente a presença de profissionais da ESF, foram consideradas relevantes em situações específicas e pontuais, reconhecendo os limites de atuação do Apoio Matricial.

As diferenças que foram identificadas entre as duas unidades básicas de saúde também influenciaram fortemente a abordagem do Nasf, uma vez que a disponibilidade dos profissionais especialistas não parece ser a mesma, sejam eles do Nasf ou matriciadores da unidade básica tradicional. 
De qualquer maneira, independentemente da abordagem que o Nasf esteja utilizando, é importante destacar que os profissionais consideraram que o Apoio Matricial atende às suas demandas e da comunidade sob sua responsabilidade.

Esse ponto merece uma reflexão sobre o quanto que o 'novo' tem a acrescentar, a transformar com sua ânsia ideológica por ressignificar seu cotidiano de trabalho, e o quanto que o 'antigo' tem a contribuir por seu tempo de experiência e acúmulo de conhecimentos. É importante reconhecer o estranhamento do novo sobre o antigo como uma contribuição para integrar as ações de forma mais efetiva, facilitando os processos de mudanças e os relacionamentos entre os profissionais e destes com os usuários dos serviços de saúde. Fala-se aqui não só dos profissionais que executam as ações, mas também dos modelos que orientam nosso agir enquanto profissionais de saúde.

Espera-se, com este estudo, contribuir com o trabalho das equipes da ESF e do Nasf, sugerindo, ainda, que novos estudos sejam realizados para melhor compreensão da dinâmica de implementação e consolidação do Apoio Matricial na AB.

\section{Referências}

BALLARIN, M. L.G. S.; BLANES, L. S.; FERIGATO, S. H. Apoio Matricial: um estudo sobre a perspectiva de profissionais da saúde mental. Interface Comunicação, Saúde, Educação, Botucatu, v. 16, n. 42, p. 767-778, jul./set. 2012.

BARBOSA, E. G. et al. Experiência da Fisioterapia no Núcleo de Apoio à Saúde da Família em Governador Valadares, MG. Fisioter. Mov., Curitiba, v. 23, n. 2, p. 323-330, abr./jun. 2010.

BARDIN, L. Análise de Conteúdo. São Paulo: Edições 70, 2011.

BRASIL. Conselho Nacional de Saúde. Resolução n. 196, de 10 de outubro de 1996. Aprova diretrizes e normas regulamentadoras de pesquisas envolvendo seres humanos. Diário Oficial [da] União. Brasília, DF, 16 out. 1996. Disponível em: <http://conselho.saude.gov.br/ resolucoes/reso_96.htm>. Acesso em: 10 jun. 2012.

Ministério da Educação. Conselho Nacional de

Educação. Diretrizes curriculares nacionais dos cursos de graduação em enfermagem, medicina e nutrição. Diário Oficial [da] União. Brasília, DF, 03 out. 2001. Disponível em: <http://portal.mec.gov.br/cne/arquivos/ pdf/2001/pces1133_01.pdf>. Acesso em: 01 ago. 2013.
. Ministério da Saúde. Secretaria de Atenção à Saúde. Departamento de Atenção Básica. Diretrizes do NASF: núcleo de apoio à saúde da família. Brasília, DF: Ministério da Saúde, 2009. (Série B. Textos Básicos de Saúde; Cadernos de Atenção Básica n. 27).

Ministério da Saúde. Secretaria de Atenção à Saúde. Departamento de Atenção Básica. Política Nacional de Atenção Básica. Brasília, DF: Ministério da saúde, 2012.

CAMPOS, G. W. S. A Clínica do sujeito: por uma clínica reformulada e ampliada. In: Saúde Paidéia. 3. ed. São Paulo: Hucitec, 2007. p. 51-67.

CHIAVERINI, D. H. (Org.). Guia prático de matriciamento em saúde mental. Brasília: Ministério da Saúde: Centro de Estudo e Pesquisa em Saúde Coletiva, 2011. Disponível em: <http://bvsms.saude.gov.br/bvs/publicacoes/guia_pratico_matriciamento_saudemental.pdf $>$. Acesso em: 20 ago. 2013.

CUNHA, G. T.; Campos, G. W. S. Apoio Matricial e Atenção Primária em Saúde. Saúde Soc., São Paulo, v. 20, n. 4, p. 961-970, dez. 2011.

DIAS, R. B.; Nogueira, F. P. S. Trabalho em Equipe. In: 
GUSSO, G; LOPES, J. M.; editores. Tratado de Medicina de Família e Comunidade. Porto Alegre: Artmed, 2012. p. 288-297.

FLICK, U. Desenho da pesquisa qualitativa. Porto Alegre: Artmed, 2009. (Coleção Pesquisa Qualitativa).

MINAYO, M. C. S. O desafio do conhecimento: pesquisa qualitativa em saúde. 12. ed. São Paulo: Hucitec, 2010.

(Org.). Pesquisa Social: teoria, método e criatividade. 31. ed. Petrópolis: Vozes, 2012.

NASCIMENTO, D. D. G.; Oliveira, M. A. C. Reflexões sobre as competências profissionais para o processo de trabalho nos Núcleos de Apoio à Saúde da Família. Mundo Saúde, São Paulo, v. 34, n. 1, p. 92-96, jan./mar. 2010.

OLIVEIRA, I. C.; Rocha, R. M.; Cutolo, L. R. Algumas palavras sobre o NASF: Relatando uma experiência acadêmica. Rev. bras. educ. med., Rio de Janeiro, v. 36, n. 4, p. 574-580, out./dez. 2012.

OLIVEIRA, R. S.; Borba, P. C.; Sampaio, Y. P. C. C. Organização de Serviço e Integração com os Núcleos de Apoio à Saúde da Família. In: GUSSO, G; LOPES, J. M. Tratado de Medicina de Família e Comunidade. v. 1. Porto Alegre: Artmed, 2012. p. 307-314.

SANTOS, A. P. L.; Lacaz, F. A. C. Apoio Matricial em Saúde do Trabalhador: tecendo redes na Atenção Básica do SUS, o caso de Amparo/ SP. Ciência \&t Saúde Coletiva, Rio de Janeiro, v. 17, n. 5, p. 1143-1150, maio 2012.

SARAIVA, A. S.; Zepeda, J. Princípios do Apoio Matricial. In: GUSSO, G.; LOPES J. M. Tratado de Medicina de Família e Comunidade. Porto Alegre: Artmed, 2012. p. 298-306.

SILVA, A. T. et al. Núcleos de Apoio à Saúde da Família: desafios e potencialidades na visão dos profissionais da Atenção Primária do Município de São Paulo, Brasil. Cadernos de Saúde Pública, Rio de Janeiro, v. 28, n. 11, p. 2076-2084, nov. 2012.

Recebido para publicação em julho de 2014

Versão final em janeiro de 2015

Conflito de interesse: inexistente

Suporte financeiro: não houve 